\title{
Pengaruh Kualitas Pelayanan Panitia Penerimaan Mahasiswa Baru terhadap Kepuasan Calon Mahasiswa di Universitas PGRI Palembang
}

\author{
Ermini $^{1 *}$, Dina Sri Nindiati ${ }^{2}$ \\ 1,2Universitas PGRI Palembang, Palembang, Indonesia
}

\section{A R T I C L E I N F O}

Article history:

Received 19 Agustus 2019 Received in revised form 16 September 2019 Accepted 15 Oktober 2019 Available online 30 November 2019

Kata Kunci:

Pelayanan, Kepuasan, Calon Mahasiswa

Keywords: Services, Satisfaction, Prospective Students

\begin{abstract}
A B S T R A K
Keberhasilan suatu perguruan tinggi sangat ditentukan oleh mutu pelayanan yang diberikan, dimana pelayanan yang bermutu dapat di identifikasi melalui kepuasan pelanggan, dalam hal ini adalah mahasiswa. Adapun tujuan dari penelitian ini adalah untuk mengetahui pengaruh kualitas layanan panitia Penerimaan Mahasiswa Baru (PMB) terhadap kepuasan calon mahasiswa di Universitas PGRI Palembang tahun 2018. Metode yang digunakan untuk mendapatkan data penelitian ini adalah dengan metode Survey.

Data dikumpulkan dengan kuisioner yang kemudian dianalisis dengan menggunakan Uji-F dan Uji-t. Hasil penelitian menunjukan,berdasarkan analisis koefisien determinasi diperoleh hasil Rsquare (koefisien determinasi) sebesar 0,606 artinya bahwa 60,6\% variabel kepuasan pelanggan dipengaruhi oleh variabel kualitas pelayanan,yang terdiri dari tangible, reliability, responsiveness, assurance dan empathy sedangakan sisanya dipengaruhi oleh variabel lain yang tidak dibahas dalam penelitian ini. Terdapat pengaruh signifikan secara parsial (individu) pada variabel tangible dan assurance terhadap kepuasan pelanggan dengan hasil signifikansi $t(0,000)<\alpha$ 0,005 . Sedangkan pengaruh variabel reliability, responsivenes, tangible menunjukkan hasil yang tidak signifikan terhadap kepuasan pelanggan dengan nilai $t(0,000)>\alpha 0,05$.
\end{abstract}

A B S T R A C T

The success of a college is largely determined by the quality of services provided, where quality service can be identified through customer satisfaction, in this case students. The purpose of this study was to determine the effect of the quality of the service of the New Student Admissions Committee (PMB) on the satisfaction of prospective students at PGRI Palembang University in 2018. The method used to obtain the data of this study was the Survey method.

Data were collected by questionnaire which was then analyzed using the F-Test and T-Test. The results showed, based on the analysis of the coefficient of determination Rsquare results obtained (determination coefficient) of 0.606 means that $60.6 \%$ of customer satisfaction variables are influenced by service quality variables, consisting of tangible, reliability, responsiveness, assurance and empathy while the rest are influenced by other variables which is not discussed in this study. There is a partially significant (individual) influence on tangible and assurance variables on customer satisfaction with a significance result of $t(0,000)<\alpha 0,005$. While the influence of the variable reliability, responsiveness, tangible showed insignificant results on customer satisfaction with a value of $t(0,000)>a 0.05$.

\footnotetext{
Corresponding author.

E-mail addresses: ermini123@gmail.com (Ermini)
} 


\section{Pendahuluan}

Pendidikan merupakan jasa yang berupa proses pembudayaan, pengertian ini berimplikasi adanya input dan output. Inputnya adalah peserta didik atau mahasiswa, sarana, prasarana dan lingkungan, sedangkan outputnya adalah jasa pelayanan pendidikan, lulusan dan alumni. Pemahaman kualitas perguruan tinggi tidak terlepas dari produk yang dikeluarkan yaitu kurikulum, penelitian, pengabdian pada masyarakat, administrasi, dan ekstrakurikuler serta produk parsial yaitu lulusan. Meskipun disebut produk parsial, lulusan perguruan tinggi adalah produk yang sangat penting, yang bersifat generatif dan aplikatif. Generatif bermakna bahwa melalui lulusanlah jasa-jasa perguruan tinggi disebarluaskan dan dikembangkan. Sedangkan dikatakan aplikatif karena lulusan akan mengaplikasikan jasajasa perguruan tinggi yang telah diterimanya dalam dunia kerja.

Sistem pendidikan berkaitan erat dengan kualitas sumber daya manusia. Hal ini didasarkan pada realitas dari suatu sistem pendidikan adalah sumber daya manusia yang akan digunakan dalam industri dan pembangunan disuatu daerah ataupun untuk negara, ini membuktikan adanya peningkatan kebutuhan masyarakat akan pendidikan formal dan menjadikan perguruan tinggi sebagai sektor jasa yang diharapkan dapat menghasilkan sumber daya manusia yang dapat diandalkan. Dalam peta persaingan antara perguruan tinggi satu dengan perguruan tinggi yang lain menuntut lembaga pendidikan lebih memperhatikan mutu pendidikan, pelayanan, dan kelembagaan di suatu perguruan tinggi baik Negeri maupun Swasta sehingga dapat mampu dan unggul dalam persaingan tersebut. Dalam hal ini perguruan tinggi perlu melakukan langkah antisipasi untuk menghadapi persaingan dan bertanggung jawab untuk menggali serta memperbaiki kinerja dengan meningkatkan segala aspek pelayanan termasuk kualitas pelayanan yang dimiliki oleh perguruan tinggi tersebut.

Keberhasilan suatu perguruan tinggi sangat ditentukan oleh mutu pelayanan yang diberikan, dimana pelayanan yang bermutu dapat di identifikasi melalui kepuasan pelanggan, dalam hal ini adalah mahasiswa. Keadaan persaingan yang kompetitif antar perguruan tinggi menuntut lembaga pendidikan harus memperhatikan mutu pendidikan dan kelembagaan sehingga mampu serta unggul dalam persaingan tersebut. Perguruan tinggi harus melakukan langkah antisipasi guna menghadapi persaingan yang semakin kompetitif serta bertanggung jawab untuk menggali dan meningkatkan segala aspek pelayanan yang dimiliki.

Berhasil atau tidaknya pelayanan dalam perguruan tinggi dipengaruhi oleh petugas pelayanan, sebab dari pelayanan inilah calon mahasiswa baru dapat memberikan penilaian terhadap pelayanan penerimaan mahasiswa baru. Dalam hal ini diperlukan untuk dapat memenangkan persaingan dengan perguruan tinggi lainnya dan menuntut adanya komitmen untuk memuaskan calon mahasiswa baru yang salah satunya perbaikan mutu pelayanan dengan cara memahami apa yang diinginkan calon konsumen atau mahasiswa baru.

Menurut Gronroos dalam bukunya Manajemen Pelayanan. Pelayanan adalah serangkaian aktivitas yang bersifat tidak kasat mata yang terjadi akibat adanya interaksi antara konsumen dengan karyawan atau hal-hal lain yang disediakan oleh suatu perusahaan, pemberi pelayanan yang dimaksudkan adalah untuk memecahkan permasalahan konsumen/ pelanggan karena ada istilah yang mengatakan bahwa Pelanggan adalah Raja. Pelayanan juga akan memberikan dampak terhadap perusahaan atau instansi pendidikan, apabila pelayanan dalam instansi tersebut buruk atau kurang baik maka para calon mahasiswa baru akan berpindah ke perguruan tinggi lainnya dan calon mahasiswa baru tersebut akan memberitahu teman teman nya ini akan menyebabkan mahasiswa yang masuk akan menurun dan mahasiswa merasa pelayanan yang diberikan oleh petugas buruk.

Kualitas pelayanan merupakan ukuran seberapa baik tingkat layanan yang diberikan sesuai harapan pelanggan. Dua faktor utama yang mempengaruhi kualitas pelayanan yaitu expected service dan perceived service. Apabila jasa yang diterima,atau dirasakan (perceived service) sesuai dengan yang diharapkan maka kualitas pelayanan dipersepsikan baik atau memuaskan, begitu sebaliknya . Tjiptono (2005:262) menyebutkan bahwa model kualitas jasa yang popular dan hingga kini banyak dijadikan acuan dalam riset pemasaran adalah model ServQual (singkatan dari service quality) yang kembangkan oleh Parasuraman, Zeithaml, dan Berry. Servqual dibangun atas adanya perbandingan dua factor utama yaitu persepsi pelanggan terima (perception service) dengan layanan yang sesungguhnya diharapkan (expected service)

Cravens menyatakan bahwa "untuk mencapai tingkat kepuasan yang tinggi diperlukan adanya pemahaman tentang apa yang diinginkan oleh konsumen, dengan mengembangkan komitmen setiap orang yang ada dalam lembaga untuk memenuhi kebutuhan konsumen." Selanjutnya menurut Simonson (1993), agar dapat memenangkan persaingan perlu memenuhi apa yang diinginkan oleh mahasiswa. 
Tindakan terbaik yang perlu dilakukan oleh lembaga pendidikan tinggi adalah menggunakan umpan balik dari mahasiswa untuk mengendalikan perubahan organisasional. Kesesuaian antara keinginan atau persepsi konsumen (customer voice) dan keinginan organisasi pengelola atau perguruan tinggi (company voice) syarat penting dalam keberhasilan proses pendidikan.

Universitas PGRI Palembang adalah salah satu universitas swasta diantara 2000 lebih universitas swasta di Indonesia yang bergerak dalam bidang jasa pendidikan. Universitas PGRI Palembang sendiri termasuk salah satu universitas terbaik di kawasan Sumatera bagian Selatan selain khususnya dalam lingkup universitas di bawah naungan Persatuan Guru Republik Indonesia (PGRI). Salah satu bentuk kegiatan yang menjadikan Universitas PGRI Palembang sebagai salah satu universitas terbaik di Sumatera Selatan adalah tentu saja proses Penerimaan Mahasiswa Baru (PMB). Panitian PMB memegang peranan penting bagaimana pandangan (image) yang terbentuk untuk universitas ini di masyarakat.

Panitia penerimaan Mahasiswa baru harus mampu menangani atau mengerti tentang semua tugas atau kegiatan yang dilakukan dalam pelayanan untuk itu pengertian dari Kegiatan penerimaan mahasiswa baru (PMB) adalah suatu kegiatan rutin yang diselenggarakan oleh universitas atau sebuah perguruan tinggi baik Negeri maupun swasta untuk merekrut atau meraih calon mahasiswa baru agar dapat tertarik kuliah di Universitas tersebut. Dalam kegiatan ini panitia juga dapat melihat dan memilih calon mahasiswa yang sesuai dengan kualitas tinggi karena dalam prosedur pendaftaran terdapat tes yang harus dilakukan oleh calon mahasiswa baru sebelum dapat masuk ke fakultas yang diinginkan.

\section{Metode}

Tempat yang akan dilaksanakan dalam penelitian ini adalah tempat pendaftaran calon mahasiswa baru Universitas PGRI Palembang kampus A (Gedung Kantin Dharma Wanita). Waktu penelitian dilaksanakan pada tanggal 18 April 2018 - 31 Agustus 2018. Dalam hal ini yang menjadi populasi penelitian adalah Calon mahahasiswa baru yang mendaftar. Dalam penelitian ini batas kesalahan yang ditolerir adalah $5 \%$ karena Populasi dalam penelitian ini cukup banyak. Dari hasil perhitungan, maka didapat jumlah sampel sebesar 125 orang.

\section{Teknik Pengumpulan Data}

(a) Data primer, Menyebarkan kuesioner yaitu berupa pertanyaan atau pernyataan ilustrasi yang disusun secara tertulis dengan menggunakan daftar pertanyaan guna memperoleh data berupa jawaban dari responden. Selain itu juga digunakan untuk memperoleh data kuantitatif yang obyektif, (b) Data Sekunder, Dalam penelitian ini melakukan studi kepustakaan yaitu mempelajari mendalam dan mengutip teori-teori atau konsep-konsep dari sejumlah literature. Baik buku-buku, jurnal, website dan yang lainnya yang berhubungan dengan objek penelitian.

\section{Teknik Analisis Data}

a. Uji Kualitas Data

1) Uji Validitas

Pengukuran validitas dalam penelitian ini menggunakan korelasi product moment dari Pearson's correlation yang rumusnya sebagai berikut:

$$
r=\frac{N \Sigma X Y-\sum X \Sigma Y}{\sqrt{\left[N \Sigma X^{2}+(\Sigma X)^{2}\right]\left[N \Sigma Y^{2}+(\Sigma Y)^{2}\right]}}
$$

Keterangan :

$\mathrm{r} \quad=$ Koefisien korelasi Pearson's Product Moment

$\mathrm{N} \quad=$ Jumlah individu dalam sampel

$\mathrm{X}=$ angka mentah untuk variabel $\mathrm{x}$

$\mathrm{Y} \quad=$ angka mentah untuk variabel $\mathrm{y}$

2) Uji Reliabilitas

Dalam melakukan pengujian reliabilitas, digunakan alat ukur berupa program komputer yaitu SPSS berikut ini adalah rumus Spearman Brown :

$$
\mathrm{r}_{\mathrm{i}}=\frac{2 \mathrm{r}_{\mathrm{b}}}{1+\mathrm{r}_{\mathrm{b}}}
$$


Keterangan :

$\mathrm{ri} \quad=$ reliabilitas internal seluruh instrument

$\mathrm{rb} \quad=$ korelasi product moment antara belahan pertama dan kedua tingkat reliabilitas kuesioner diukur dengan teknik belah dua yang dipergunakan untuk kuesioner yang berbentuk angket.

b. Pengujian Hipotesis

1) Analisis Regresi Linier Berganda

Analisis data yang digunakan untuk menguji hipotesis dalam penelitian ini yaitu dengan menggunakan analisis regresi berganda, dengan rumus sebagai berikut :

$$
\mathrm{Y}=\mathrm{a}+\mathrm{bX} 1+\mathrm{cX} 2 \ldots+\mathrm{e}
$$

Keterangan :

Y = Persepsi

$\mathrm{X}=$ Kualitas Pelayanan

$\mathrm{a}=$ nilai intercept (konstan)

$\mathrm{b}=$ Koefisien regresi

$\mathrm{x} 1=$ tangibel

$\mathrm{x} 2$ = realibility

$\mathrm{x} 3=$ Responsivinees

$\mathrm{x} 4=$ Assurance

$\mathrm{x} 5=$ Emphaty

$\mathrm{e}=$ error

2) Pengujian Koefisien Determinasi R2

Pengujian koefisien determinasi digunakan untuk mengetahui seberapa besar varian dari variabel dependen dijelaskan oleh variabel independen. R2 yang digunakan adalah R2 yang mempertimbangkan dari jumlah variabel independent dalam suatu model disebut juga dengan R2 yang telah disesuaikan (Adjusted-R2). Dalam penelitian ini peneliti menggunakan Adjusted-R2 karena menurut Singgih Santoso (2000:167), apabila jumlah variabel independent yang akan diteliti lebih dari dua maka menggunakan adjusted-R2. Rumus adjusted-R2 dengan rumus sebagai berikut :

$$
\text { Adjusted }-R^{2}=1-\left(1-R^{2}\right) \frac{n-1}{n-k}
$$

Keterangan :

Adjusted-R2 = Koefisien determinasi disesuaikan

R2 $\quad$ Koefisien determinasi

$\mathrm{n} \quad \quad=$ Jumlah sampel pengamatan

$\mathrm{k} \quad \quad=$ Jumlah variabel

3) Uji F

Nilai F menunjukan pengujian variabel independen secara keseluruhan dan serentak mempengaruhi variabel dependen secara signifikan. Dalam penelitian ini uji $\mathrm{F}$ dilakukan dengan bantuan program komputer SPSS. Pengujiannya adalah apabila nilai signifikasi atau nilai probabilitas $(\mathrm{p})<0,05$, maka uji F nya signifikan sedangkan Ho nya ditolak. Prosedur yang dilakukan untuk uji F sebagai berikut:

a) Hipotesis yang akan diuji adalah :

Ho : Tidak ada pengaruh variabel independen secara bersamasama terhadap variabel dependen

Ha : Ada pengaruh variabel independen secara bersama-sama terhadap variabel dependen Mencari formulasi F hitung :

$$
\text { Fhitung }=\frac{R^{2} / k}{\left(1-R^{2}\right)(n-k-1)}
$$

Keterangan:

$\mathrm{R} 2$ = koefisien determinasi

$\mathrm{k}=$ banyaknya predictor 
$\mathrm{n}=$ banyaknya populasi

a) Menentukan kriteria pengujian

Apabila nilai probabilitas (p) $<0,05$, maka uji F signifikan dan Ho ditolak. Apabila nilai probabilitas (p) $>0,05$ maka uji F tidak signifikan dan Ho diterima

4) Ujit

Nilai t menunjukan pengujian pada variabel independen secara individu guna melihat apakah variabel independen secara individu berpengaruh secara signifikan terhadap variabel dependen dengan mengasumsikan variabel lainnya tetap atau konstan. Dalam hal ini terdapat langkah-langkah pengujian sebagai berikut :

1) Hipotesis yang akan diuji adalah

Ho : tidak ada pengaruh variabel independen secara individual terhadap variabel dependen $\mathrm{Ha}$ : ada pengaruh variabel independen secara individual terhadap dependen

b) Mencari formulasi hitung :

$$
t=\frac{\beta_{i}}{\operatorname{Se}\left(\beta_{i}\right)}
$$

Keterangan :

${ }^{\beta} \mathrm{i}=$ Koefisien regresi

Se $\left({ }^{\beta} \mathrm{i}\right)=$ Standar error koefisien regresi

c) Menentukan kriteria pengujian

Nilai t dihitung dengan uji sisi, karena hipotesis yang diuji untuk mengetahui pengaruhnya. Sehingga pengaruhnya ada dua kemungkinan adalah positif atau negatif. Apabila nilai probabilitas $(\mathrm{p})<0,05$ maka uji t signifikan dan Ho ditolak. Apabila nilai probabilitas (p) > 0,05 maka uji t tidak signifikan dan Ho diterima.

\section{Hasil dan pembahasan}

\section{Analisis Regresi Linier Berganda}

Analisis regresi linear berganda dalam penelitian ini menggunakan bantuan aplikasi SPSS Statistics Versi 20. Bentuk persamaannya adalah:

\section{$\mathrm{KCMB}=\alpha+\beta \_1 \mathrm{~Tb}+\beta \_2 \mathrm{Rb}+\beta_{-} 3 \mathrm{Rp}+\beta_{-} 4 \mathrm{Ar}+\beta_{-} 5 \mathrm{Ep}+\mathrm{e}$}

Maka berdasarkan hasil analisis dengan menggunakan program SPSS dapat disajikan persamaan regresi linear berganda sebagai berikut:

Tabel 1. Analisis Regresi Linier Berganda

\section{Coefficients $^{a}$}

\begin{tabular}{|c|c|c|c|c|c|c|}
\hline \multirow[b]{2}{*}{ Mode } & & \multicolumn{2}{|c|}{ Unstandardized Coefficients } & \multirow{2}{*}{$\begin{array}{c}\begin{array}{c}\text { Standardized } \\
\text { Coefficients }\end{array} \\
\text { Beta }\end{array}$} & \multirow[b]{2}{*}{$t$} & \multirow[b]{2}{*}{ Sig. } \\
\hline & & B & Std. Error & & & \\
\hline \multirow[t]{6}{*}{1} & (Constant) &, 955 &, 260 & & 3,673 &, 000 \\
\hline & Tangibles & .167 &, 083 & .177 & 1,998 &, 048 \\
\hline & Reliability & 071 &, 094 &, 077 & .752 & 454 \\
\hline & Responsiveness & .013 &, 086 &, 016 & .150 & 881 \\
\hline & Assurance & .453 &, 091 &, 493 & 4,971 &, 000 \\
\hline & Emphaty &, 079 & 077 & .100 & 1,028 & ,306 \\
\hline
\end{tabular}

a. Dependent Variable: Kepuasan

Sumber : Data Primer Diolah, 2019 
$\mathrm{KCMB}=0,955+0,167 \mathrm{~Tb}+0,071 \mathrm{Rb}+0,013 \mathrm{Rp}+0,453 \mathrm{Ar}+0,079 \mathrm{Ep}$

Berdasarkan persamaan tersebut, maka dapat dijelaskan sebagai berikut:

1) Koefisien konstanta sebesar 0,955 , artinya jika tidak ada variabel tangible, variabel reliability, variabel responsiveness, variabel assurance, dan variabel emphaty, maka kepuasan calon mahasiswa baru akan sebesar 0,955 poin.

2) Koefisien regresi variabel tangible adalah 0,167 berarah positif, artinya setiap peningkatan pada kualitas bukti fisik sebesar 1 poin dan variabel lainnya tetap, maka kepuasan calon mahasiswa baru akan mengalami kenaikan sebesar 0,167 poin.

3) Koefisien regresi variabel reliability adalah 0,071 berarah positif, artinya setiap peningkatan pada kualitas kehandalan panitia PMB sebesar 1 poin dan variabel lainnya tetap, maka kepuasan calon mahasiswa baru akan mengalami kenaikan sebesar 0,071 poin.

4) Koefisien regresi variabel responsiveness adalah 0,013 berarah positif, artinya setiap peningkatan pada kualitas daya tanggap panitia PMB sebesar 1 poin dan variabel lainnya tetap, maka kepuasan calon mahasiswa baru akan mengalami kenaikan sebesar 0,013 poin.

5) Koefisien regresi variabel assurance adalah 0,453 berarah positif, artinya setiap peningkatan pada kualitas jaminan panitia PMB sebesar 1 poin dan variabel lainnya tetap, maka kepuasan calon mahasiswa baru akan mengalami kenaikan sebesar 0,453 poin.

6) Koefisien regresi variabel emphaty adalah 0,079 berarah positif, artinya setiap peningkatan pada kualitas kepedulian panitia PMB sebesar 1 poin dan variabel lainnya tetap, maka kepuasan calon mahasiswa baru akan mengalami kenaikan sebesar 0,079 poin.

\section{Uji Hipotesis}

Sebelum melihat hasil pengujian terhadap hipotesis, maka perlu diketahui bahwa yang menjadi hipotesis statistik dalam penelitian ini adalah :

\section{1) Uji T}

Uji parsial ini menggunakan Uji T, yaitu:

Ho diterima jika thitung $<\mathrm{t}$ tabel pada $\alpha=5 \%$

Ha diterima jika thitung $>\mathrm{t}$ tabel pada $\alpha=5 \%$

Berikut akan dijelaskan pengujian masing-masing secara parsial

Tabel 2. Uji T

\section{Coefficients $^{a}$}

\begin{tabular}{|c|c|c|c|c|c|c|}
\hline \multirow{2}{*}{\multicolumn{2}{|c|}{ Model }} & \multicolumn{2}{|c|}{ Unstandardized Coefficients } & \multirow{2}{*}{$\begin{array}{c}\begin{array}{c}\text { Standardized } \\
\text { Coefficients }\end{array} \\
\text { Beta }\end{array}$} & \multirow[b]{2}{*}{$t$} & \multirow[b]{2}{*}{ Sig. } \\
\hline & & B & Std. Error & & & \\
\hline \multirow[t]{6}{*}{1} & (Constant) &, 955 &, 260 & & 3,673 &, 000 \\
\hline & Tangibles &, 167 &, 083 &, 177 & 1,998 & 048 \\
\hline & Reliability &, 071 &, 094 &, 077 & .752 & 454 \\
\hline & Responsiveness &, 013 &, 086 &, 016 &, 150 & 881 \\
\hline & Assurance & .453 &, 091 & ,493 & 4,971 &, 000 \\
\hline & Emphaty &, 079 &, 077 &, 100 & 1,028 &, 306 \\
\hline
\end{tabular}

a. Dependent Variable: Kepuasan

Sumber : Data Primer Diolah, 2019

Hasil pengujian hipotesis secara parsial melalui uji $t$ diperoleh $t$ hitung berdasarkan nilai koefisien yang dapat dilihat pada tabel 23, menunjukan bahwa :

a) Tangible atau bukti fisik berpengaruh walaupun tidak signifikan terhadap kepuasan calon mahasiswa baru dengan thitung $>$ ttabel sebesar 1,998 > 1,980. Besar pengaruh bukti fisik terhadap kepuasan calon mahasiswa baru adalah sebesar $17,7 \%$. Hasil pengujian $\mathrm{H}_{1}$ dalam penelitian ini menyatakan bahwa variabel tangible berpengaruh signifikan terhadap kepuasan calon mahasiswa dengan arah hubungan positif. Jadi dengan demikian $\mathrm{H}_{1}$ diterima.

b) Reliability atau kehandalan tidak berpengaruh signifikan terhadap kepuasan calon mahasiswa baru dengan thitung $>$ ttabel sebesar $0,752<1,980$. Besar pengaruh bukti fisik terhadap kepuasan calon 
mahasiswa baru adalah sebesar 7,7\%. Hal ini bukan berarti bahwa aspek kehandalan tidak penting, akan tetapi variabel kehandalan tetap memiliki pengaruh walaupun tidak signifikan. Hasil pengujian $\mathrm{H}_{2}$ dalam penelitian ini menyatakan bahwa variabel reliability tidak berpengaruh signifikan terhadap kepuasan calon mahasiswa dengan arah hubungan positif. Jadi dengan demikian $\mathrm{H}_{2}$ ditolak.

c) Responsiveness atau daya tanggap tidak berpengaruh signifikan terhadap kepuasan calon mahasiswa baru dengan thitung $>$ ttabel sebesar 0,150 < 1,980. Besar pengaruh bukti fisik terhadap kepuasan calon mahasiswa baru adalah sebesar 1,6\%. Hasil pengujian $\mathrm{H}_{3}$ dalam penelitian ini menyatakan bahwa variabel responsiveness tidak berpengaruh signifikan terhadap kepuasan calon mahasiswa dengan arah hubungan positif. Jadi dengan demikian $\mathrm{H}_{3}$ ditolak.

d) Assurance atau jaminan berpengaruh signifikan terhadap kepuasan calon mahasiswa baru dengan thitung > ttabel sebesar 4,971 >1,980. Besar pengaruh bukti fisik terhadap kepuasan calon mahasiswa baru adalah sebesar 49,3\%. Hasil pengujian $\mathrm{H}_{4}$ dalam penelitian ini menyatakan bahwa variabel assurance berpengaruh signifikan terhadap kepuasan calon mahasiswa baru dengan arah hubungan positif. Jadi dengan demikian $\mathrm{H}_{4}$ diterima.

e) Emphaty atau empati tidak berpengaruh signifikan terhadap kepuasan calon mahasiswa baru dengan thitung $>$ ttabel sebesar 1,028 < 1,980. Besar pengaruh bukti fisik terhadap kepuasan calon mahasiswa baru adalah sebesar $10 \%$. Hasil pengujian $\mathrm{H}_{5}$ dalam penelitian ini menyatakan bahwa variabel emphaty tidak berpengaruh signifikan terhadap kepuasan calon mahasiswa baru dengan arah hubungan positif. Jadi dengan demikian $\mathrm{H}_{5}$ ditolak.

\section{Uji F}

Berdasarkan hasil pengujian statistik (Uji Anova/Uji F), dilihat pada tabel sebagai berikut :

Tabel 3. Uji F

ANOVA $^{a}$

\begin{tabular}{|ll|r|r|r|r|r|}
\hline Model & & \multicolumn{1}{c|}{$\begin{array}{l}\text { Sum of } \\
\text { Squares }\end{array}$} & df & Mean Square & F & Sig. \\
\hline 1 & Regression & 20,942 & 5 & 4,188 & 36,650 &, $000^{\circ}$ \\
& Residual & 13,599 & 119 &, 114 & & \\
& Total & 34,541 & 124 & & & \\
\hline
\end{tabular}

a. Dependent Variable: Kepuasan

b. Predictors: (Constant), Emphaty, Tangibles, Assurance, Reliability, Responsiveness

Sumber : Data Primer Diolah, 2019

Pada tabel 3, diperoleh bahwa nilai $\mathrm{F}=36,650$ dengan tingkat probability $(0,000<0,05)$. Setelah mengetahui besarnya $\mathrm{F}$ hitung, maka akan dibandingkan dengan $\mathrm{F}$ tabel. Kemudian dicari pada distribusi nilai $F$ tabel dan ditemukan nilai $F$ tabel sebesar 2,29. Karena nilai $F$ hitung 36,650 lebih besar dari nilai $F$ tabel sebesar 2,29, maka dapat ditarik kesimpulan bahwa variabel bebas $\mathrm{X}_{1}, \mathrm{X}_{2}, \mathrm{X}_{3}, \mathrm{X}_{4}$, dan $\mathrm{X}_{5}$ (secara simultan) berpengaruh terhadap variabel terikat (Y).

\section{Uji Koefisien Determinan $\left(R^{2}\right)$}

Uji koefisien determinan dilakukan untuk melihat besarnya pengaruh tangible, reliability, responsiveness, assurance, dan emphaty terhadap kepuasan calon mahasiswa baru. Adapun determinan yang diperoleh adalah sebagai berikut:

Model Summary

\begin{tabular}{|l|c|r|r|r|}
\hline Model & $\mathrm{R}$ & $\mathrm{R}$ Square & $\begin{array}{c}\text { Adjusted R } \\
\text { Square }\end{array}$ & $\begin{array}{c}\text { Std. Error of } \\
\text { the Estimate }\end{array}$ \\
\hline 1 &, $779^{a}$ &, 606 &, 590 & .33805 \\
\hline
\end{tabular}

a. Predictors: (Constant), Emphaty, Tangibles, Assurance, Reliability, Responsiveness 
Dapat dijelaskan bahwa R2 = 0,606 yang berarti menjelaskan besarnya pengaruh tangible, reliability, responsiveness, assurance, dan emphaty terhadap kepuasan calon mahasiswa baru adalah sebesar 60,6\% dan sisanya sebesar 39,4\% dijelaskan variabel lainnya.

\section{Simpulan dan saran}

Penelitian ini bertujuan untuk mengetahui pengaruh variabel Tangible (Tb), variabel Reliability $(\mathrm{Rb})$, variabel Responsiveness (Rp), variabel Assurance (As), dan variabel Emphaty (Ep) terhadap kepuasan calon mahasiswa baru pada Penerimaan Mahasiswa Baru di Univerisitas PGRI Palembang. Penelitian ini untuk mengetahui variabel mana yang paling dominan diantara variabel bebas tersebut. Beranjak dari rumusan masalah, maka dapat ditarik kesimpulan yaitu :

1. Tangible atau bukti fisik berpengaruh walaupun tidak signifikan terhadap kepuasan calon mahasiswa baru dengan thitung $>$ ttabel sebesar 1,998 > 1,980. Jadi dengan demikian H1 diterima.

2. Reliability atau kehandalan tidak berpengaruh signifikan terhadap kepuasan calon mahasiswa baru dengan thitung $>$ ttabel sebesar 0,752 < 1,980. Jadi dengan demikian H2 ditolak.

3. Responsiveness atau daya tanggap tidak berpengaruh signifikan terhadap kepuasan calon mahasiswa baru dengan thitung $>$ ttabel sebesar 0,150 <1,980. Jadi dengan demikian H3 ditolak.

4. Assurance atau jaminan berpengaruh signifikan terhadap kepuasan calon mahasiswa baru dengan thitung > ttabel sebesar 4,971 > 1,980. Jadi dengan demikian H4 diterima.

5. Emphaty atau empati tidak berpengaruh signifikan terhadap kepuasan calon mahasiswa baru dengan thitung $>$ ttabel sebesar $1,028<1,980$. Jadi dengan demikian H5 ditolak.

6. Tangible, Reliablitiy, Responsiveness, Assurance dan Emphaty panitia Penerimaan Mahasiswa Baru (PMB) berpengaruh terhadap kepuasan calon mahasiswa baru Universitas PGRI Palembang. Hal ini dibuktikan dengan hasil statistik Fhitung sebesar 36,650 dengan signifikasi sebesar 0,000. Oleh karena itu, nilai siginifikansi lebih kecil dari $0,05(0,000<0,05)$.

\section{Daftar Rujukan}

Afrinda Khoirista, dkk. 2015. Pengaruh Kualitas Pelayanan Terhadap Kepuasan Pelanggan (Survey Pada Pelanggan Fedex Express Surabaya). Jurnal Administrasi Bisnis (JAB) Universitas Brawijaya. Vol. 25 (2) Edisi Agustus. $p: 1-7$.

Atik, dkk. 2005. Manajemen Pelayanan, disertai dengan pengembangan model konseptual penerapan citizen's charter dan standar pelayanan minimal. Yogyakarta: Pustaka Pelajar

Bergin, S. 1997. Communication is the Key to Customer Success, Transportation and Distribution. March.

Boediono. 2003. Pelayanan Prima Perpajakan. Jakarta : Rineka Cipta.

Handayani, dkk. (2003). Analisis Kepuasan Pemakai terhadap Pelayanan Perpustakaan Nasional Provinsi Daerah Istimewa Yogyakarta". Jurnal Sosiosains, Vol. 17 No. 2, April 2003. Yogyakarta: Pasca Sarjana Fisipol UGM.

Hardiati, Ratih. 2010. Analisis Pengaruh Kualitas Pelayanan Terhadap kepuasan konsumen (Menggunakan jasa penginapan (villa) Agrowisata Kebun Teh Pagilaran). Skripsi. Universitas Diponegoro.

Hasibuan, Malayu. 2005. Dasar-Dasar Perbankan. Jakarta : PT Bumi Aksara.

Ihalauw, John dan Ristiyanti Prasetijo. 2005. Perilaku Konsumen. Yogyakarta: Andi

Merdian, Wili Andri. 2007. Analisis Pengaruh Kualitas Pelayanan Terhadap Kepuasan Pelanggan (studi kasus TIKI cabang Jogjakarta). Skripsi. Universitas Sanata Dharma Yogyakarta.

Muafi, dkk. 2007. Anteseden Ekuitas Merek Perguruan Tinggi: SEM dengan Pendekatan Two Step". Jurnal Manajemen Usahawan Indonesia. No. 03 TH. XXXVI. 
Mulyana, Deddy. 2008. Ilmu Komunikasi Suatu Pengantar. Bandung: PT. Remaja Rosdakarya

Nurrianto Al Arif, M. 2010. Dasar-Dasar Pemasaran Perbankan Syariah. Bandung CV. Afabeta, 2010.

Prihantoro, A. 2012. Analisis Dimensi Kualitas Pelayanan Jasa Terhadap Kepuasan Mahasiswa di Asekolah Tinggi Agama Islam Negeri Tulungagung. Jurnal Otonomi Vol. 12 No.1.

Panji, N., A. 2007. Analisis Faktor-Faktor Kualitas Pelayanan Yang Mempengaruhi Kepuasan Mahasiswa Pada Perguruan Tinggi “Aub” Surakarta. Diakses tanggal 30 Januari 2013

Rakhmat, Jalaludin. 2001. Psikologi komunikasi edisi revisi. Bandung: PT. Remaja Rosdakarya

Sutisna. 2001. Perilaku Konsumen dan Komunikasi Pemasaran. Bandung: PT. Remaja Rosdakarya.

Tjahjono, Ahmad. 2003. Perpajakan Indonesia. Jakarta :PT. Grafindo Persada.Nura Ruslia, 2011, Analisis Faktor-Faktor Yang Berpengaruh Terhadap Kinerja Sistem Informasi Akuntansi, Skripsi, Universitas Pasundan.

Tjiptono, Fandy. (2004). Prinsip-prinsip Total Quality Service (TQS). Yogyakarta: Andi Yogyakarta.

Pratiwi Elsa. 2010. Pengaruh Profitabilitas, Financial Leverage, dan Pertumbuhan Perusahaan terhadap Tindakan Perataan Laba. Jurnal Akuntansi 1(3): 1-23.

Pratomo et.al. 2009. Reksa Dana Solusi Perencanaan Investasi di Era Modern. PT. Garamedia Pustaka Utama. Jakarta

Reichheld, F.F \& Izak. (1996), The Loyalty Effect, Harvard Business School Press, Boston, MA.

Robbins, Stephen P,, 2005, Organizational Behavior, Elevent Edition, International Edition, Pearson Education inc,, San Diego State University, Upper Saddle river, New jersey

Romney, Marshall B, \& pal Jhon Steinbart, 2009, Accounting Information System, Eleventh Edition, Prentice Hall

Sadatamrul, 2004, Hubungan Antara Partisipasi Dalam Pemgembangan Sistem Informasi Dengan Perkembangan Penggunaan Teknologi Informasi (Suatu Tinjauan Dengan Dua Faktor Kontijensi), Seminar Nasional Akuntansi VII, 2-3 Desember

Salam, Darma Setyawan, 2007, Manajemen Pemerintahan Indonesia,Jakarta : Djambatan

Sedarmayanti, 2009, Sumber Daya Manusia dan Produktivitas Kerja, Bandung: CV, Mandar Maju

Sekaran, Uma. 2006. Research Methods For Business (Metodologi Penelitian untuk Bisnis). Jakarta: Salemba Empat.

Setianingsih, I. 2008. "Sistem Pengendalian Internal atas Aktiva tetap pada Fakultas Ekonomi Univesitas Sumtra Utara”. Diploma III Fakultas Ekonomi Universitas Sumatra Utara.

Manajemen Sumber Daya Manusia Reformasi Birokrasi dan Manajemen Pegawai Negeri Sipil, Bandung: Rafika ADITAMA

Sofyandi, Herman, 2008, Manajemen Sumber Daya Manusia, Penerbit: Graha Ilmu, Yogyakarta

Sugiarto Prajitno. 2006. Analisis faktor-faktor Yang Berpengaruh Terhadap Kinerja SIA Dengan Kompleksitas Tugas sebagai Variabel Moderating, Jurnal Akuntansi.

Sugiyono. 2008. Metode penelitian Bisnis. Bandung : edisi Revisi. Cetakan Delapan Belas, CV, Alafabetha. 
Supomo dan Nur Indriantoro. 2009. Pengaruh Partisipasi Terhadap Kepuasan Pemakai Dalam Pengembangan Sistem Informasi Dengan Kompleksitas Tugas, Kompleksitas Sistem dan Pengaruh Pemakai Sebagai Moderating Variable. Jurnal Analisis Bisnis dan Ekonomi, Vol.2 (2): p 105-123.

Sutrisno, Edy. 2009. Manajemen Sumber Daya Manusia. Edisi Pertama. Cetakan Pertama. Jakarta. Penerbit: Kencana..

Szajna dan Scammell, 1993. "The Effect of Information System User Expectation on Their Performance and Perception". MIS Quartely.

Terry, George R, dan Rue, Leslie W, 2005, Dasar-Dasar Manajemen, Jakarta : Bumi Aksara.

Veithzal, 2004, Manajemen Sumber Daya Manusia Untuk Perusahaan dari Teori KePraktik. Jakarta : PT. Raja Grafindo Persada.

Wibowo. 2007. Sistem Akuntansi dan Informasi. Terjemahan Marianus Sinaga. Erlangga, Jakarta.

Wijaya. (2004). Kamus Lengkap Inggris-Indonesia. Semarang: Bintang Jaya.

Wilkinson, Joseph, W, 2010, Accounting Information System, Fourth Edition, United States, New York, Jhon Wilwy and Sons Inc.

Wood, R. E. 1986. Task Complexity. Definition of The Construct. Organizational Behaviour and Human Decision Process, pp.60-82.

Wulandari. 2006. Karakteristik Good Corporate Governance. Alfabeta. Bandung. 